\title{
Editorial
}

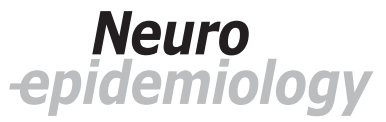

\section{Neuroepidemiology from 1982 to 2007 and Beyond}

It is an honour, a pleasure and a challenge for me to take over the Editor-in-Chief of Neuroepidemiology position from Prof. Gustavo C. Román, who, together with the Editorial Board, has guided the journal successfully through the past 6 years. Under their outstanding leadership Neuroepidemiology acquired a more prominent status among the specialty journals, with the current impressive impact factor of 2.352 . Therefore, I would like to commend the previous leadership for their significant achievements. I would also like to welcome the new Editorial Board members, all of whom are well-known experts in different fields of neurology, epidemiology, and clinical trials. It is a particularly great pleasure and honour to have with us Prof. John F. Kurtzke who has been a member of the Editorial Board since the first issue of the first volume of Neuroepidemiology in 1982. Since its inception in 1982 under the leadership of Dr. Bruce S. Schoenberg followed by Dr. Milton Alter, Dr. Philip B. Gorelick, and Dr. Gustavo C. Román, the journal has evolved very rapidly into one of the leading and internationally recognized journals in neurology and clinical epidemiology. Indeed, Neuroepidemiology is the only international journal devoted to the study of neurological disease distribution and determinants of frequency in human populations. However, in the current highly competitive environment it is vitally important not only to maintain the momentum but evolve the journal even further. In this article, I would also like to outline recent and forthcoming changes in the journal policies/strategies to address the challenge.

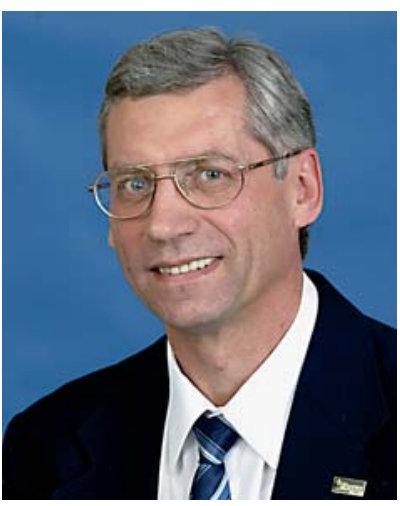

Traditionally, original research publications in Neuroepidemiology were confined to non-experimental studies. However, a randomized controlled trial is no more than a cohort study in which the investigator(s) allocate(s) the exposure being studied to the participants in a random manner. Therefore, at the last meeting of the previous Editorial Board, it was rightfully suggested to expand the focus and scope of publications acceptable by the journal to include studies based on clinical research, including clinical trials and clinically relevant methods. This important change in the publication strategy has recently been implemented in our new Guidelines for $\mathrm{Au}$ thors and we now welcome submissions based on clinical trials/research. In line with this change, we altered the aims and scope of the journal.

\begin{tabular}{ll}
\hline KARGER & $\begin{array}{l}\text { @ 2008 S. Karger AG, Basel } \\
\text { 0251-5350/08/0301-0001\$24.50/0 }\end{array}$ \\
$\begin{array}{l}\text { Fax +41 61 306 1234 } \\
\begin{array}{l}\text { E-Mail karger@karger.ch } \\
\text { www.karger.com }\end{array}\end{array}$ & $\begin{array}{l}\text { Accessible online at: } \\
\text { www.karger.com/ned }\end{array}$
\end{tabular}


We also plan to have regular state-of-the-art reviews on specific topics. Other important changes in the current Guidelines for Authors include ethical requirements for submitted manuscripts, suggested reporting guidelines, detailed structured arrangements and printing style of the submitted manuscripts, and an increase of the allotted size of paper published free of charge $(2,500$ words or approximately 11 double-spaced manuscript pages, including tables, illustrations and references, for original research papers and 5,000 words or approximately 22 double-spaced manuscript pages, including tables, illustrations and references, for reviews and methodological papers). Recently, journal articles published before 1998 (1982-1997) have become searchable and downloadable from the journal website in PDF fulllength article format. To speed up the reviewing process and increase its objectivity, we recently increased the number of reviewers required/allocated for each submitted manuscript to 3 (in selected cases even to 4 ) and shortened the turnaround time required to complete and submit the review by reviewers to 12 days.

The current manuscript acceptance rate is about $30 \%$ and is likely to be even lower in 2008 due to steadily increasing number of submissions to the journal, so only the highest possible quality manuscripts will be published. There have also been recent changes in the on-line manuscript submission and reviewing system aimed to reduce time from submission of manuscript to first editorial decision (currently, 26 days) and elapsed time from acceptance to publication of manuscripts first on-line (currently, 75 days) and then in print (currently, 140 days). There is a strategy in place to further substantially reduce time from acceptance of the manuscript to its publication. The journal cover and website homepage have also received a new look better reflecting the journal aims and scope. With all these recent changes, future planned improvements and new Editorial Board members in place we are determined to serve our authors with rapid and fair reviews and decisions.

With this in mind, let me invite neurologists, epidemiologists, clinicians, trialists and other health professionals who work in the field of neurological disease distribution and determinants of frequency in human populations to share with us the results of their research. I would like to conclude this article by a quote from the first Editor-in-Chief of the journal and founder of Neuroepidemiology, Dr. Bruce S. Schoenberg, who stated that 'no journal can be successful without readers. I hope our efforts and performance will merit your continued interest in and support of Neuroepidemiology'. This statement was made in 1982 but it also holds true now.

Valery L. Feigin Editor-in-Chief 